\section{The doctor's dilemma}

David Weatherall

The Cambridge World History of Human Disease. Edited by Kenneth F. Kiple. Cambridge University Press: 1993. Pp. 1,176. £75, \$150.

THE Concise Oxford Dictionary defines a handbook as "a short manual or guide book". Usage has certainly changed over the years. Between 1883 and 1886 the New Sydenham Society published Charles Crighton's translation of August Hirsch's monumental two-volume Handbuch der Historisch-geographischen Pathologie. This remarkable work, which first appeared between 1860 and 1864 , attempted to catalogue everything that was then known about the historical, pathological, social and geographical aspects of disease. Not surprisingly, noone tried to repeat this tour de force, that is until about eight years ago when Cambridge University Press and a large international editorial board decided to attempt this daunting task. The product of the long gestation is this extremely large and handsome offspring of Hirsch.

As a co-editor of a textbook of medicine, which, though it will soon reappear in three volumes, covers only a small fraction of the field encompassed by the Cambridge World History, I was particularly interested to see how such a vast work would be organized. And how would the editors avoid those embarrasing letters reminding them of their sins of omission, in our case ranging from such dreadful gaffes as hiccough and priapism to musicogenic epilepsy, a condition which, though it does not pose a considerable public health problem, means a lot to those who suffer an unpleasant spasm each time the national anthem is played? All of us have our pet disease and, not unreasonably, do not expect it to be neglected in a Who's Who of pathology.

The Cambridge World History, like the English hymnal, wanders freely between the ancient and modern. After brief essays on the history of Western, Chinese and Islamic medicine, there are accounts of changing concepts of disease, medical specialities, preventative medicine and ways of measuring health. The story is rounded off by an extensive description of the history of disease in different parts of the world and the present-day geography of disease, and by 158 essays on individual diseases, both current concepts and historical perspectives. Surprisingly, and thanks to an ingenious two-part 75-page index, it is quite easy for readers to find their way round this vast maze of pathology.

Of course, the editors had one large problem that did not face Hirsch in the nineteenth century: what to omit? In some key sections a few examples have had to suffice. To illustrate how concepts of disease have changed, heart disease, mental illness, cancer and sexual deviation are chosen. This works fairly well, but the range of subjects used to illustrate medical specialities and disease prevention is more idiosyncratic. Genetic disease, paediatrics and tobaccorelated disease, here renamed tobaccosis, are understandable, but given the rich range of possibilities under these headings it is not clear why chiropractic and addiction come so high on the list. On the other hand, the extensive accounts of the history of human disease in different parts of the world include some excellent essays and, like those on the present-day geography of disease, contain material that would be difficult to find anywhere else summarized in such a compact and scholarly way.

The selection of the 158 diseases that form the subjects of individual essays must have been a nightmare for the editors. In the end they settled for a preponderance of infectious diseases and several disorders that have disappeared with time, including chlorosis, that strange variety of anaemia so loved by medical historians. But why ainhum and not appendicitis; and catarrh, diarrhoea and dropsy, but not that endemic scourge of Westernization and memorial to the arctic plumbing arrangements of British public schools and ancient universities, constipation?
Was it all worth it? With some reservations I think it was. Because of the huge arena covered, this is not a reference book for historians or medical specialists in their narrow fields. They are bound to find errors and omissions. Having a particular interest in genetic and haematological diseases, I was not happy about the balance and content of either of these subjects. And when I looked up my personal pet disease, thalassaemia, the commonest inherited disorder in man, I was dismayed to read that "it is most frequent in areas where ancient Greek immigration was most intense", a rather dated treatment of a condition that is now known to have

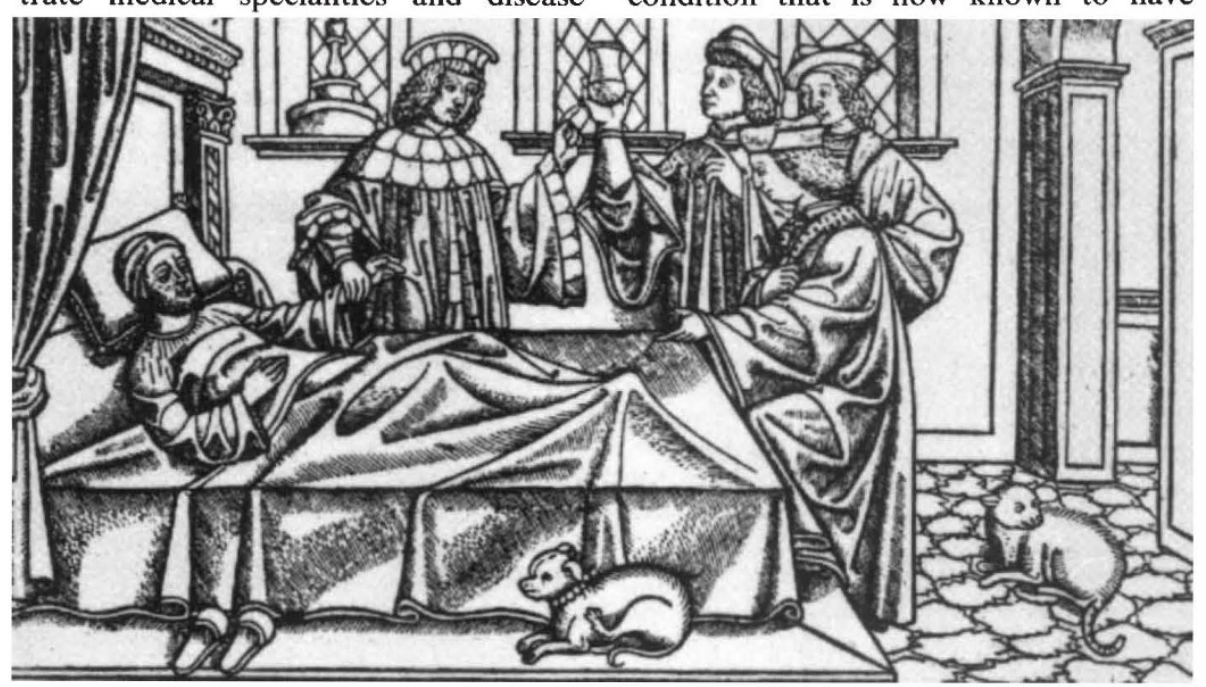

Doctor in the house - this woodcut appears on the title page of PIIny et al.'s Aurem opus (Pavla, 1516) and is reproduced from Medicine and the Five Senses, a collection of essays edited by W. F. Byrum and R. Porter. CUP, £40, $\$ 59.95$.

arisen by different mutations all over the tropical world and which affects hundreds of thousands of children in India and South-East Asia.

But the first edition of a work of this scope must inevitably lack balance in parts and contain some inaccuracies. Viewed in a broader perspective it represents a considerable achievement that brings together in one volume many of the diverse roots of modern medical practice and hence makes this absorbing story available to a much wider audience than has hitherto been possible. At a time when both historians and practitioners of science and medicine are concentrating on small and highly specialized areas of their subjects, and when undergraduate and postgraduate curricula are increasingly overcrowded, general reviews of this kind are welcome. Provided that a few of the problems of fact and balance can be ironed out in future editions, this new work could become a worthy successor to Hirsch's remarkable effort.

David Weatherall is in the Institute of Molecular Medicine, John Radcliffe Hosnital, Oxford OX3 9DU, UK. 